\title{
LA BIOPOLÍTICA Y SUS CONSECUENCIAS SOCIALES LA BIOPOLÍTICA Y SUS CONSECUENCIAS SOCIALES
}

Manuel Augusto Vicente Otazu ${ }^{t}$

\section{RESUMEN}

La biopolítica es la administración de la vida mediante el poder en alianza con la tecnología para plasmar decisiones políticas y llevarlas a cabo. En la tecnocracia se hace referencia a la estructura de poder que concibe a la sociedad como un conjunto de sistemas técnicos orientados a través del conocimiento que proporcionan las diferentes disciplinas científicas. La responsabilidad en la toma de decisiones recae entonces sobre aquellas personas que acreditan competencia en la identificación de las soluciones óptimas para resolver conflictos, de un modo eficiente en la práctica y presuntamente neutral en lo ideológico. El progreso sociopolítico se identifica así con el progreso tecnocientífico, consumando de este modo los ideales del racionalismo ilustrado. Se debe agregar que se ha producido un giro tecnodigital que no solo afecta a la naturaleza, a la vida y al planeta; sino también a la conformación de los sujetos, las relaciones sociales y la concepción de lo humano mismo. Se impone entonces replantearse los postulados de la epistemología, para que logre desarrollarse al ritmo marcado por el despliegue de la ciencia y la tecnologia, y atienda así mismo a los problemas que se desprenden de la inserción de los productos científicos en la sociedad. Considero que representa un desafio para los teóricos de la ciencia y una obligación ética e intelectual para los profesionales tanto de la educación, el derecho, la sociología o la medicina.

Palabras clave: epistemología, biopolítica, dignidad.

\begin{abstract}
Biopolitics is the administration of life through the power in alliance with technology to express political decisions and carry them out. In the technocracy, it refers to the power structure that conceives society as a group of technical systems oriented through knowledge that provide the different scientific disciplines. The responsibility for decision-making falls upon those who accredit competence in identifying optimal solutions to resolve conflicts in an efficient way in practice and ideologically neutral. The socio-political progress is so identified with the techno-scientific progress, thus consummating the ideals of the Enlightenment rationalism. It should be added that there has been a techno digital turn that not only affects the nature, life and the planet; but also to the formation of subjects, social relations and the concept of humanity itself. Prevails then rethink the principles of epistemology, to achieve developed at the pace set by the deployment of science and technology, and likewise attend to the problems arising from the integration of scientific products in society. I think that is a challenge for theorists of science and ethics and intellectual obligation for teachers, law, sociology and medicine.
\end{abstract}

Keywords: epistemology, biopolitics, dignity.

\section{INTRODUCCIÓN}

Para comprender lo erótico que pude resultar la Biopolítica contaré la leyenda de Mirra, ella era la hija del rey de Siria, deseaba apasionadamente a su padre, y como el incesto está exento de culpa para los dioses del Olimpo, Afrodita socorrió a la enamorada princesa. Mirra, por esos misterios que solo las divinidades conocen, logró poseer a su padre muchas noches sin que este se diera cuenta de nada, pero al cabo de dos semanas, el rey clamó a los dioses por el abuso del que había sido objeto, y como no todos los seres superiores son tan permisivos como Afrodita, aparecieron agentes de las fuerzas celestiales que castigaron a Mirra convirtiéndola en árbol. Sin embargo, el cambio de forma no incidió en su deseo. Aquello que en la versión humana de la princesa había sido flujo hormonal, en su versión vegetal se convirtió en aroma de mirra.

Pero tantas noches de amor dieron su fruto. Nueve meses después de la metamorfosis, un niño surgió de su arbórea vagina: Adonis, "El que le da placer a las mujeres". Siendo pequeño ya se lo disputaban las diosas por su demasiada belleza y calidez. Fueron tantas las peleas en las que se trenzaron las deidades por la posesión de Adonis que, finalmente, por mandato de Artemisa, "La rústica diosa cazadora y virgen", el joven fue destrozado por los jabalíes. Las gotas de sus heridas se iban convirtiendo en pétalos sanguinolentos. Ese es el quimérico origen de las rosas.

\footnotetext{
'Magister en Ciencias de la Educación con mención en Psicología Educativay Tutoría Escolar. Universidad Alas Peruanas, Universidad Privada de Tacna. Correoelectrónico:m_augusto30@hotmail.com
} 
Vicente, M. La Biopolítica y sus Consecuencias Sociales

Las mujeres griegas con mucha pasión evocaban el mito de Adonis mediante una fiesta anual que los varones toleraron a regañadientes. Mucho sabían los hombres griegos sobre la estrecha relación entre lo erótico y lo político. Las reflexiones que Platón pone en boca de Sócrates en Banquete y en Fedro son prueba de ello. Por su parte, las mujeres, exiliadas del poder y del gobierno, encontraron en el erotismo y en Adonis su propia manera de hacer política. Festejaron y resistieron la opresión mediante una peculiar celebración del mito.

Las mujeres atenienses, en las fiestas de Adonis, no avanzaban sobre el ágora ni sobre otros espacios tradicionalmente viriles. Andaban por los tejados. Hacían corrillos, danzaban, bebían alcohol, cantaban, cuchicheaban, reían maliciosas, quemaban incienso y mirra e intercambiaban mimos sexuales.

"La muerte de Adonis significaba el comienzo de la fertilidad de la tierra y en primavera. Pero, en su recreación urbana, la fiesta acontece hacia fin del verano y el marchitarse de la planta significa el florecimiento del deseo. Lo sexual es a la ciudad, lo que la fertilidad es al campo" (Diaz, 1990).

El poder desarrollado en base a la biopolítica, en esta realidad neoliberal apremia poder disciplinar y el poder biopolítico, los cuales adiestran y prolongan la vida humana, pero también la vigilan y ordenan para que esta pueda ser útil a la reproducción de la vida y también del capital, para ello el biopoder utiliza, en los albores del siglo XXI, una serie de controles, biológicos, gubernamentales y de organización social, que se expanden por todas las estructuras sociales para generar subjetividades que diseñan el mundo; por lo tanto, tras un primer ejercicio del poder sobre el cuerpo que se produce en el modo de la individualización, tenemos un segundo ejercicio que no es individualizado sino masificado, por decirlo así, que no se dirige al hombre sino al hombre especie para manipularlo e ir en contra de la dignidad humana.

Los epistemólogos reconocen que la tecnología merece merecen una atención especial para involucrar los problemas que no surgen de la ciencia; al ser la tecnología una ciencia aplicada, sin embargo otros autores cuestionan la relación entre la ciencia y la tecnología; la tecnología está sujeta a las necesidades o deseos del cliente; estos problemas del hombre son a menudo problemas en términos sociales, derivados del capitalismo, que mejor serían satisfechas por algún tipo de injerencia social. En defensa de la vista de la ingeniería, que tal vez se podría decir que el repertorio de formas "probadas" de la interferencia social es escaso. La tentación de soluciones técnicas se podría superar, al menos así, es como un ingeniero lo vería por la inclusión de las ciencias sociales en el desarrollo sistemático y la aplicación del conocimiento a los problemas humanos; eficiencia en el uso de la energía y el uso de materiales, es entonces a menudo un valor primordial. Bajo la presión de la sociedad, otros valores han llegado a ser incorporados: la seguridad y la sostenibilidad; los ingenieros tienen como objetivo maximizar esto a favor del éxito del mercado el cual solo puede ser evaluado después de los hechos.

Los desafíos de la ingeniería genética, por ejemplo, y los desarrollos de las tecnologías digitales nos fuerzan a encarar nuevamente la pregunta sobre los límites de la tecnología y de la ciencia. Los poderes asociados con la tecnociencia instrumentan la administración de la vida de las poblaciones bajo el paradigma de lo Biopolítico. A partir de este nuevo devenir tecnocientífico se imponen nuevas categorías de análisis para pensar en una renovación de la filosofía frente a los cambios en los saberes y en las prácticas sociales. El mercado no es natural y la competencia, en consecuencia, tampoco; la competencia es una idea un principio de formalización de una lógica y una estructura interna; la competencia entre nosotros por el poder es perversión por más que se quiera tener una mejor especie humana, al intentar hacerlo la estamos corrompiendo bajo una política activa neoliberal, estos mecanismos competitivos regulan la economía, esta sociedad se ha convertido en una empresa; el homo economicus neoliberal es el hombre de la empresa y la producción; sociedad de empresa y sociedad judicial son dos caras de la misma moneda, por lo tanto, están bajo un sistema económico jurídico injusto perverso y bajo el dominio de la ley del más fuerte, del más poderoso que reconsidera una mejor especie frente al tercer mundo.

\section{A EPISTEMOLOGÍA Y LOS MECANISMOS DE PODER}

La Epistemología, puede ser un buen lugar para la crítica del mundo establecido. Se trata de criticar ese mundo en sus fundamentos, en la lógica que lo anima, en las bases de las formas del saber con que ha revestido su poder. Se trata de hacer pensable un mundo distinto, una biopolítica distinta, un futuro mejor que el que ofrecen las bombas atómicas, la manipulación genética, la era de la digitalización general. Contribuir a ese objetivo es mi propósito; primero debemos demarcación, es decir, poner límites; demarcar es un concepto que introdujo Karl Popper, el cual lo aplicaríamos a las Ciencias Sociales. Popper fijaba que si no aplica o supiera utilizar el método científico, está afuera, los que usan el método están dentro de la ciencia y los que no, están fuera de ella, es decir, el método es demarcatorio por sí mismo. El asunto es que, si uno no sabe qué conjunto de reglas conduce a la verdad, se podría tener al menos un 


\section{La Vida y la Fistaria}

Vicente, M. La Biopolítica y sus Consecuencias Sociales

criterio para saber cuándo estamos dentro o cuándo estamos fuera. Otro tipo de criterio, que no sea puntualmente metodológico, aunque permita sugerencias metodológicas generales es el "Empirismo Lógico", que es una reformulación, en términos de demarcación, de lo que había sido el Inductivismo. De alguna forma lo que se llama «Falsacionismo», es una reformulación del Convencionalismo, en términos del problema de la demarcación.

Sostengo que las críticas, lógicas e históricas, que se formularon contra el Empirismo Lógico y contra el Falsacionismo son tan demoledoras que no hay realmente un criterio, lógicamente consistente y un consenso aceptable, que permita distinguir formalmente entre la ciencia y la pseudo-ciencia; y esto, como se comprenderá, es bastante grave, por lo que debo enfatizar aquí mi responsabilidad en estas conclusiones, que no son generalmente compartidas por algunos filósofos de la ciencia, salvo por una minoría extravagante, a la que me enorgullezco de pertenecer; Pero el asunto es aún más grave cuando afirmo que alguno de estos problemas no tienen solución, pero es necesario el hilo argumentativo para sostenerlo

El "Tratado contra el Método" de Feyerabend nos abre bien los ojos, tiene como subtítulo: "Esquema de una teoría anarquista del conocimiento". Feyerabend dice que es anarquista. Recordemos que Feyerabend fue falsacionista, discípulo de Popper, al principio, muy Popperiano, luego hasta imperar en sus propias posturas adquiere personalidad, El Feyerabend que me interesa es ese, el que rompe esquemas, el que asume, radicalmente la teoría de los paradigmas de Thomas Kuhn. Pero tiende a entender los paradigmas no sólo como teorías o conjuntos de supuestos comunes, sino más bien, como grupos de intereses, como gremios, o como expresiones de poder. Esto significa que en Feyerabend los paradigmas son al mismo tiempo teorías pero también tienen expresión institucional, son figuras de poder. Lo que significa poner el énfasis en la capacidad que tienen los paradigmas de considerar las refutaciones como anomalías no sólo en el plano teórico sino, también en la capacidad práctica, en la capacidad institucional, de pelear por un status científico, por una teoría científica, por una legitimidad científica excluyente, con herramientas que están más al borde de la ciencia,

Feyerabend piensa de manera radical la tesis de inconmensurabilidad que ha planteado Thomas Kuhn. En su teoría los paradigmas son radicalmente inconmensurables e intraducibles, lo que hace, que sean equivalentes entre sí, es decir, se podría elegir por cualquiera de ellos convencionalmente. Son equivalentes porque son inconmensurables, de esto se llega a la conclusión de que no hay progreso en la historia de la ciencia. Porque no habría manera de establecer cuando un paradigma es mejor que otro. En términos de Lakatos, no habría ningún criterio de evaluación de teorías que sea puramente interno a la actividad científica. Obviamente esta es una tesis que parece, en principio, bastante extravagante.

Por otro lado, racionalidad de la ciencia es al hecho de que la práctica científica consiga su objetivo, es decir, decimos que hay racionalidad en la práctica científica en la medida en que avanza hacia el objetivo que se propone, que es, en principio, la búsqueda de la verdad o, al menos, la verosimilitud. Pero, si esto es así, entonces Feyerabend manifiesta que no hay una racionalidad interna en la ciencia. Es importante notar, sin embargo, que aunque desde un punto de vista teórico, la teoría de Aristóteles, la de Newton y la de Einstein serían equivalentes, los científicos, sin embargo, se cambiaron del paradigma de Aristóteles al de Newton y del de Newton al de Einstein. Lo que Feyerabend sostiene es que no se cambiaron por razones científicas sino políticas. La ciencia cambia, no progresa. Y cuando cambia no cambia por razones científicas, no cambia por razones internas. Si cambia es por razones externas. Según Feyerabend las teorías científicas que triunfan son las que están asociadas a los poderes dominantes, las que expresan el poder. La racionalidad de la ciencia es una racionalidad exterior. Las teorías científicas triunfan cuando se hacen verosímiles respecto de los poderes dominantes, y prevalecen mientras mantengan esa consonancia. El poder dominante siempre es el del más fuerte, si analizamos el darwinismo social como una teoría social que propugna que la teoría de la evolución de Charles Darwin tiene aplicaciones sociales en instituciones humanas. Está basado en la idea de la supervivencia del más apto concebido como mecanismo de evolución social y la creencia de que el concepto Darwiniano de la selección natural puede ser usado para el manejo de la sociedad humana, por lo tanto, basándose en esta teoría no me sorprendería que en un futuro sea aceptado la eugenesia y sus consecuencias. Foucault considera que los discursos, como el positivismo científico, son desfasados, demuestra cómo estas prácticas discursivas están articuladas con prácticas poco éticas. En la arqueología del conocimiento, se propone mostrar las relaciones que existen entre las prácticas discursivas y las no discursivas con relación al poder; en resumen, el poder produce discursos, aparentemente "verdaderos" y esto es fanatismo y corrupción. Foucault se propone mostrar cómo el poder produce discursos que pretenden ser "verdaderos", cuando son contingentes, es decir, cómo se encuentran articulados con el poder, la política y los discursos de ideales por él producidos. De esta manera, se encuentran íntimamente relacionados: mecanismos 
de poder, efectos de verdad, reglas de poder y poder de los mencionados discursos verdaderos. Por lo tanto, estos discursos imperantes del positivismo lógico, la ciencia y su prostituta: la tecnología, son solo consecuencia del poder y de ahí se deriva sus consecuencias éticas. La metafísica ha estado en crisis, ha recibido severas críticas, las principales son las que provienen del positivismo lógico, para quien la metafísica es un discurso ridículo, sin significado, porque sus enunciados son afirmaciones acerca de los cuales nunca se podrá tener una experiencia. No obstante, debemos decir claramente que los temas concernientes a la metafísica no fueron dejados a un lado en el siglo XX, sino, por el contrario, las distintas corrientes de pensamiento se ven remitidas a ellos con la necesidad de formular maneras alternativas en su tratamiento.

\section{BIOPOLÍTICA Y BIOPODER}

El primo de Darwin formuló los principios de eugenesia que significa ciencia del bien nacido. El Estado de Indiana da la primera ley eugenésica en 1907; cuyo modelo se propaga en 30 estados, la cual aprueba la esterilización de quienes fueran considerados locos o imbéciles por un equipo de expertos. Cuatro años después, en una conferencia de prensa que tiene lugar en la Corte Suprema de los Estados Unidos de América, el Juez Presidente desenmascara la ideología de esa ley. El movimiento Eugenésico estadounidense es financiado por fundaciones como el instituto Carnegie y la Fundación Rockefeller. En 1906, Kellogg financia la Fundación para la mejora de la raza en Michigan y Henry Ford, la EugenicsReccord Office. La época más importante de esterilización en EEUU es entre 1927 y 1963. Se calcula que 64000 personas son esterilizadas forzosamente para evitar la transmisión de enfermedades a la siguiente generación; conocemos que en el Perú hay varios ejemplos de reformas de control de la natalidad, esterilización forzada que va contra los derechos humanos y la dignidad de las personas.

Para Foucault la eugenesia y la medicalización de las perversiones son las dos grandes tecnologías de Biopoder las cuales se fundamenta por igual en una cadena de perversión-herencia-degeneración todo ello junto con las prácticas de control social, médicaspsiquiátricas, pedagógicas, jurídicas que alcanzan su perfección en el racismo de estado

La Biopolítica comienza con mayor auge con el neoliberalismo y la tecnología, todas las grandes instituciones comienzan a ocuparse de la vida como negocio, la muerte como negocio, los enfermos como un gran negocio para la venta de fármacos, como por ejemplo en la psiquiatría, o vacunas contra virus cada vez más novedosos, lucran con la dignidad de los miembros de sus comunidades. De este modo, con la excusa del cuidado de la salud de los gobernados, se asegura un mayor control sobre los sujetos, sujetados al poder. La escuela, las iglesias, el ejército, el estado y demás instituciones se ocupan de difundir dietas, cirugías, regulación alimenticia, control de la natalidad, actividades físicas, prohibiciones, promoción de la donación de órganos y otras medidas "sacralizadas" en tanto se emiten en nombre de la salud y la seguridad. En efecto el capitalismo se configura así desde una moral aséptica respecto del cuerpo. Esa restricción ética incidió en las prácticas y colaboró a fortalecer la situación económica de quienes demostraban poder, prueba de ello era su prosperidad económica así como su salud física y moral. Esta nueva ética de las pulsiones corporales, ponía un énfasis especial en administrar los impulsos, ejemplo, el consentimiento informado, la fecundación y la descendencia. He aquí el nacimiento del Biopoder. No obstante, esto entraña un peligro porque la idea de pertenecer a un sector privilegiado de la especie fue una de las condiciones de posibilidad de racismo moderno, pues quienes ejercen el poder se consideran de una especie superior.

\section{ENFOQUE FILOSÓFICO DE LA DIGNIDAD HUMANA}

La idea de dignidad humana ha sido objeto de numerosos debates filosóficos y ocupa un lugar relevante en el derecho internacional, el criterio de la dignidad humana está en las posiciones de Kant y Habermas en torno del concepto de "Dignidad humana" los cuales son muy acertados. Como es sabido, Kant hace una distinción entre "valor" y "dignidad", concibe la "dignidad" como un valor intrínseco de la persona moral, la cual no admite equivalentes. La dignidad no debe ser confundida con ningún objeto, con ninguna mercancía, dado que no se trata de nada útil ni intercambiable o provechoso. Lo que puede ser manipulable, reemplazado y sustituido no posee dignidad, sino precio. Cuando a una persona se le pone precio se la trata como a un objeto o una mercancía. "Persona es el sujeto cuyas acciones son imputables (...) Una cosa es algo que no es susceptible de imputación ", de ahí que la ética, según Kant, llegue solo hasta "Los límites de los deberes recíprocos de los hombres". En cuanto ser dotado de razón y voluntad libre, el ser humano es un fin en sí mismo, es un ser capaz de hacerse preguntas morales, de discernir entre lo justo y lo injusto, de distinguir entre acciones morales e inmorales; en efecto, los seres moralmente imputables son fines en sí mismos, esto es, son seres autónomos y merecen un respeto incondicionado. El 


\section{La Vida y la Histaria}

Vicente, M. La Biopolítica y sus Consecuencias Sociales

valor de la persona no remite al mercado ni a apreciaciones meramente subjetivas (de conveniencia, de utilidad, etc.), sino que proviene de la dignidad que le es inherente a los seres racionales libres y autónomos. En consecuencia, la autonomía moral es el concepto central con que Kant caracteriza al ser humano y constituye el fundamento de la dignidad humana: " $L a$ autonomía, es, pues, el fundamento de la dignidad de la naturaleza humana y de toda naturaleza racional". Esta caracterización moral marca una diferencia entre los animales y los seres humanos, y, a la vez, deja abierto un espacio para el respeto a otros seres que pudieran ser moralmente imputables"; Dorando J. M., (2010); Estos argumentos que esgrime en relación con el tratamiento que debe darse a la vida humana y a las personas esta referencia a la dignidad humana es un principio en diferentes constituciones nacionales y declaraciones internacionales, como un valor fundamental que legitima los demás principios; el problema es la aplicación frente a la duda del valor metafísico de la dignidad humana, en mi opinión no es necesario un soporte metafísico, seria perder el tiempo en explicar ontológicamente la dignidad humana en vez de trabajar por llegar a un consenso, Wittgenstein se preguntaba: ¿Será siempre ventajoso cambiar un retrato poco claro por otro bien nítido?, por supuesto que no es ventajoso; si bien es cierto tenemos razón y libertad sin embargo es algo que no se vio de forma neutral sino bajo algún discurso autoritario, holístico o bajo un marco religioso o metafísico para asentar su legitimidad.

La dignidad se explica en buena medida por la "autonomía" propia del ser humano, como se lee ya en Platón, Kant y Habermas; La justificación de la concepción de dignidad que en los textos jurídicos aparece ligada a los derechos humanos, los derechos se desprenden de la dignidad. En efecto la Declaración Universal de los Derechos Humanos se ha convertido en una referencia clave en el debate ético-político y filosófico actual, y el lenguaje de los derechos se ha incorporado a la conciencia colectiva de muchas sociedades. Sin embargo, en lás ciencias políticas sobre la naturaleza, fundamentación, contenido e incluso sobre la existencia de los derechos humanos; hay claros problemas en cuanto a su eficacia, dado que existe una gran desproporción entre lo violado y lo garantizado estatalmente.

En mi opinión, gracias al Naturalismo Darwiniano, a partir de una concepción de los seres humanos como hijos del azar o productos fortuitos de la evolución; esto me lleva a desconfiar de la metafísica como base de la dignidad, los Darwinianos como yo compartimos las sospechas Nietzscheanas sobre la otra mundanidad de las ideas absolutas Platónicas a mi parecer inexistente y darle un firme sustento
Naturalista. Recordemos que para Platón el cuerpo es la cárcel del alma, es una bestia torpe a la cual hay que castigar para que el alma luego de varias reencarnaciones vuele al mundo de las ideas, no coincido con tales argumentos; en efecto los Naturalistas en principio y luego Freud, Foucault y Derrida me han desencantado en mi búsqueda trascendental o sueño metafísico al no usar lo que Derrida Denomina "Una completa presencia que está más allá del juego", y rechazar tanto como lo hace él, los varios reemplazantes de Dios que han sido propuestos para el papel de esa completa presencia. Esto significa que debemos dejar abierto la puerta para acceder a un tipo de creencia mejor que la que tenemos con el fin que nos haga más felices o al menos de mejores resultados sociales. El Filósofo Goodman argumenta que no hay un solo "modo" de interpretar el mundo, no hay una sola forma de representarlo objetivamente pero hay muchos modos de actuar para concretar nuestra felicidad y debemos buscar la mejor posible para nuestra sociedad.

\section{CONSECUENCIAS BIOPOLÍTICAS EN LA SOCIEDAD}

En Grecia se desarrolló una ética vinculada con la regulación de la propia vida como preparación para un futuro gobierno de la ciudad, que implica el gobierno de la vida de los otros. Se trataba de una ética del cuidado de sí, en función del otro.

Hoy en día; la frase de Sócrates"conócete a ti mismo" se cambia por el "preocúpate de ti mismo". Hay que ocuparse de sí mismo para poder realmente llegar a conocerse. Ahora bien, ¿En qué consiste ese ocuparse? En implementar un cuidado de sí iluminado por principios éticos. Sin embargo, esos principios no surgían de una moral que promulgara códigos a ser cumplidos, sino problematizados de gran libertad para la construcción permanente de la moral. Problematizaciones en lugar de recetas. ¿Cómo utilizar los placeres para disfrutarlos sin dañarme?, ¿Cómo tratar al otro para establecer una relación fructuosa?, ¿Qué debo controlar?, ¿Qué permitir?, ¿Sería posible hacer una obra de arte con mi propia vida?.

No solo del poder sino también de la tecnología se incrementa para manipular los secretos de la vida, los encierros del deseo y los controles ejercidos sobre los cuerpos; se lograron robots electrónicos y, más tarde, robots digitales. Hoy todas esas realidades y esas fantasías confluyen en los cyborgs.

"Un cyborg es un ser híbrido surgido de la genética y la electrónica. Biológico y maquínico al mismo tiempo. Ser vivo atravesado por tecnología. Criatura tecno científica y ficción. Artificio posorgánico y poshumano que no cometerá los mismos 
errores del ser humano pero estará bajo nuestro control. Estamos asistiendo a una vuelta de tuerca de la evolución, nos estamos convirtiendo en máquinas; ¿Cuánta tecnología atraviesa nuestro cuerpo?, medicamentos, implantes, transplantes, inseminación artificial, clones, prótesis, en fin", (Diaz, 2010), en efecto esta sociedad es un mercado biopolítico, se incita un discurso que crea una ciencia sobre la sexualidad y su control; entonces el hombre y su dignidad está en juego porque es el producto histórico de una red de biopoder sin ningún tipo de esencia atemporal.

"Marx define al hombre como el ser vivo que trabaja y usa un lenguaje. En general, las definiciones de lo humano coinciden al considerarlo como aquello que "está en el medio" entre la naturaleza y la cultura, entre lo racional y la intuición, lo consciente y lo inconsciente, lo ideal y lo material; en el medio de esta dualidad. Pero, los sujetos contemporáneos hemos reconvertido esa relación, Incorporamos en nuestros cuerpos los productos de la técnica, la naturaleza y la cultura, dejaron de ser dos extremos que se tocan. Somos una fusión de ambos. ¿Cuánto de natural queda en nosotros? Actuamos incluso contra la naturaleza, porque vivimos (y sobrevivimos) penetrados por la técnica. Las religiones monoteístas aspiraban a eternizar la vida espiritual, la tecno ciencia en cambio pretende eternizar la vida biológica", (Diaz, 2010).

\section{CONCLUSIONES}

La propuesta de Foucault es la de ver las cesuras y los problemas de la constitución de las ciencias humanas y develar su racionalidad instrumental. Es decir, la aparición de la ciencia como propuesta de ilustración y como práctica de esclavitud parece importar delimitar el margen, el borde, lo excluido del discurso positivista lógico, al valorar un texto, reviste tanto o más importancia lo que se excluye que lo que se dice, las ciencias de la naturaleza, como las ciencias del espíritu tienen un mismo origen las tecnologías del poder detrás cada discurso o cada ideología.

Todas las grandes instituciones comienzan a ocuparse desde la salud como negocio hasta la manipulación genética de la vida y la muerte de los miembros de sus comunidades, con la excusa del cuidado de la salud de los gobernados, se asegura un mayor control sobre los sujetos. La escuela, las iglesias, el difundir dietas, cirugías, regulación alimenticia, control de la natalidad, prohibiciones, salud y seguridad.

Darwin, los naturalistas en principio y luego Freud, Foucault y Derrida me han desencantado en mi búsqueda trascendental o sueño metafísico de buscar un fundamento metafísico y esencial como base para sostener la dignidad humana.

Solo hay el deseo de poder en lo social, y esto genera represión y mortíferas acciones de la reproducción social que son producidas por el deseo narcisista, debemos poner más atención al problema del otro, como fin en sí mismo y no como medio de manipulación.

\section{REFERENCIAS BIBLIOGRÁFICAS}

Bunge, M. (1973). La investigación científica. Editorial Ariel, Barcelona.

Diaz E., (1990), La condición política del erotismo, Página web, Una mirada filosófica, Buenos Aires En línea: http://www.estherdiaz.com.ar/textos/politica_erotismo.h tm

Dorando J. M., (2010), Dignidad humana en Kant y Habermas, Revista Estudios de filosofía práctica e historias de las ideas vol.12, M endoza, En línea: http://www.scielo.org.ar/scielo.php

Diaz E., (2010), El rigor científico y sus consecuencias biopolíticas como propedéutica para una filosofía de la educación, Revista Educación Unisinos, Buenos Aires En línea: http://revistas.unisinos.br/index.php/educacao/article/vi ewFile/452/123;

Foucault, M. (1994). Hermenéutica del Sujeto. Editorial la Piqueta, Madrid.

Foucault, M. (1989). La estructura de la interpretación genealógica, en el yo minimalista y otras conversaciones, Editorial la Piqueta, Madrid.

Simon, J. (2002). La dignidad del hombre como principio regulador de la bioética. Revista de derecho y genoma humano. Págs. 25-42.

Popper, K. (1967). La lógica de la investigación científica. Editorial Tecnos, Madrid.

Lakatos, I. (1983). La metodología de los programas de investigación científica, Alianza Editorial, Madrid.

Maturana, H. y Varela F. (1988). El árbol del conocimiento, las bases biológicas del entendimiento humano. Editorial, Lumen, Santiago.

Feyerabend P., (1984). Tratado contra el método. Editorial Tecnos, Madrid. 